\title{
Targeted lung cancer screening selects individuals at high risk of cardiovascular disease.
}

DOI:

10.1016/j.lungcan.2018.08.006

10.1016/j.lungcan.2018.08.006

\section{Document Version}

Accepted author manuscript

Link to publication record in Manchester Research Explorer

\section{Citation for published version (APA):}

Balata, H., Knight, S., Barber, P., Colligan, D., Crosbie, E., Duerdan, R., Elton, P., Evison, M., Greaves, M., Howells, J., Irion, K., Karunaratne, D., Kirwan, M., Macnab, A., Mellor, S., Miller, C., Newton, T., Novasio, J., Sawyer, R., ... Crosbie, P. (2018). Targeted lung cancer screening selects individuals at high risk of cardiovascular disease. Lung Cancer, 124, 148-153. https://doi.org/10.1016/j.lungcan.2018.08.006, https://doi.org/10.1016/j.lungcan.2018.08.006

\section{Published in:}

Lung Cancer

\section{Citing this paper}

Please note that where the full-text provided on Manchester Research Explorer is the Author Accepted Manuscript or Proof version this may differ from the final Published version. If citing, it is advised that you check and use the publisher's definitive version.

\section{General rights}

Copyright and moral rights for the publications made accessible in the Research Explorer are retained by the authors and/or other copyright owners and it is a condition of accessing publications that users recognise and abide by the legal requirements associated with these rights.

\section{Takedown policy}

If you believe that this document breaches copyright please refer to the University of Manchester's Takedown Procedures [http://man.ac.uk/04Y6Bo] or contact uml.scholarlycommunications@manchester.ac.uk providing relevant details, so we can investigate your claim.

\section{OPEN ACCESS}




\title{
Targeted lung cancer screening selects individuals at high risk of cardiovascular disease.
}

H Balata $^{1}$, S Blandin Knight ${ }^{1}$, P Barber ${ }^{1}$, D Colligan ${ }^{2}$, EJ Crosbie ${ }^{3}$, R Duerdan ${ }^{4}$, P Elton ${ }^{5}$, M Evison ${ }^{1}$, M Greaves ${ }^{4}$, J Howells ${ }^{6}$, K Irion ${ }^{7}$, D Karunaratne ${ }^{7}$, M Kirwan $^{8}$, A Macnab ${ }^{9}$, S Mellor ${ }^{10}$, C Miller ${ }^{9}$, T Newton $^{10}$, J Novasio ${ }^{8}$, R Sawyer ${ }^{4}$, A Sharman ${ }^{4}, \mathrm{~K}$ Slevin ${ }^{8}$, E Smith ${ }^{4}$, B Taylor ${ }^{11}$, S Taylor ${ }^{2}$, J Tonge ${ }^{2}$, A Walsham ${ }^{12}$, S Waplington ${ }^{2}$, J Whittaker ${ }^{13}$, R Booton ${ }^{1}$, PAJ Crosbie ${ }^{1+3^{*}}$.

\begin{abstract}
${ }^{1}$ Manchester Thoracic Oncology Centre, North West Lung Centre, Manchester University NHS Foundirst ation Trust, Southmoor Road, Wythenshawe, UK. ${ }^{2}$ Manchester Health and Care Commissioning, Manchester, UK. ${ }^{3}$ Division of Cancer Sciences, Faculty of Biology, Medicine and Health, University of Manchester, Manchester, UK. ${ }^{4}$ Department of Radiology, Manchester University NHS Foundation Trust, Southmoor Road, Wythenshawe, UK. ${ }^{5}$ Greater Manchester Health \& Social Care Partnership, Manchester, UK. ${ }^{6}$ Department of Radiology, Royal Preston Hospital, Preston, UK. ${ }^{7}$ Department of Radiology, Manchester Royal Infirmary, Manchester University NHS Foundation Trust, Manchester, UK. ${ }^{8}$ Thoracic Oncology Research Hub (TORCH), Manchester University NHS Foundation Trust, Southmoor Road, Wythenshawe, UK. ${ }^{9}$ Department of Cardiology, Wythenshawe Hospital, Manchester University NHS Foundation Trust, Southmoor Road, Wythenshawe, UK. ${ }^{10}$ Department of Radiology, Royal Blackburn Hospital, Blackburn, UK. ${ }^{11}$ Department of Radiology, The Christie NHS Foundation Trust, Manchester, UK. ${ }^{12}$ Department of Radiology, Salford Royal NHS Foundation Trust, Salford, UK. ${ }^{13}$ Department of Radiology, Stockport NHS Foundation Trust, Stockport, UK.
\end{abstract}

*Corresponding author: Dr Phil Crosbie, North West Lung Centre, Manchester University NHS Foundation Trust, Southmoor Road, Wythenshawe, M23 9LT. Tel +44 (0)161 291 2116. E-mail: philip.crosbie@manchester.ac.uk 


\begin{abstract}
Background: Cardiovascular disease (CVD) is a major cause of morbidity and mortality in populations eligible for lung cancer screening. The aim of this study was to determine whether a brief CV risk assessment, delivered as part of a targeted community-based lung cancer screening programme, was effective in identifying individuals at high risk who might benefit from primary prevention.

Methods: The Manchester Lung Screening Pilot consisted of annual low dose CT (LDCT) over 2 screening rounds, targeted at individuals in deprived areas at high risk of lung cancer (age 55-74 and 6year risk $\geq 1.51 \%$, using PLCO $_{\mathrm{M} 2012}$ risk model). All participants of the second screening round were eligible to take part in the study. Ten-year CV risk was estimated using QRISK2 in participants without CVD and compared to age ( \pm 5 years) and sex matched Health Survey for England (HSE) controls; high risk was defined as QRISK2 score $\geq 10 \%$. Coronary artery calcification (CAC) was assessed on LDCT scans and compared to QRISK2 score.
\end{abstract}

Results: Seventy-seven percent $(n=920 / 1,194)$ of screening attendees were included in the analysis; mean age $65.6 \pm 5.4$ and $50.4 \%$ female. QRISK2 and lung cancer risk (PLCO $\left.{ }_{\mathrm{M} 2012}\right)$ scores were correlated $(\mathrm{r}=0.26, \mathrm{p}<0.001)$. Median QRISK2 score was 21.1\% (IQR 14.9-29.6) in those without established CVD $(77.6 \%, n=714 / 920)$, double that of HSE controls $(10.3 \%$, IQR 6.6-16.2; $n=714)$ $(\mathrm{p}<0.001)$. QRISK2 score was significantly higher in those with CAC $(\mathrm{p}<0.001)$. Screening attendees were 10-fold more likely to be classified high risk (OR 10.2 [95\% CI 7.3-14.0]). One third (33.7\%, $\mathrm{n}=310 / 920$ ) of all study participants were high risk but not receiving statin therapy for primary CVD prevention.

Discussion: Opportunistic CVD risk assessment within a targeted lung cancer screening programme is feasible and is likely to identify a very large number of individuals suitable for primary prevention. 


\section{Introduction}

Lung cancer is the world's leading cause of cancer death; most patients have advanced incurable disease at the time of diagnosis and consequently survival is poor. Early detection, through targeted screening of 'high-risk' subjects using low dose CT (LDCT) scans, has been shown to reduce lung cancer-specific mortality by $20 \%$ (1). In the large, randomised-controlled National Lung Screening Trial (NLST), a 'high-risk' population was selected for screening according to age and tobacco smoke exposure as the main drivers of lung cancer risk. A leading cause of death in the NLST study was cardiovascular disease (CVD) $(1,2)$, reflecting the considerable overlap in risk factors for the two diseases. It has been proposed that lung cancer screening programmes should incorporate cardiovascular risk assessment as a way of optimising the health benefit of screening (3). In the UK, the National Institute for Health and Care Excellence (NICE) recommends primary prevention of CVD in individuals with a 10-year risk of cardiovascular event $\geq 10 \%$ (4-6). QRISK2 is a widely-used UK-validated cardiovascular risk calculator, parameters used include: age, sex, ethnicity, deprivation, smoking status, relevant medical history (diabetes, rheumatoid arthritis, atrial fibrillation, chronic kidney disease and hypertension requiring treatment), cholesterol/HDL ratio, systolic blood pressure and body mass index (BMI) (https://www.qrisk.org/2017/). Missing data are assigned by the calculator using age and sex-based average values. Those at high risk are recommended interventions to optimise their CV health, including stopping smoking, attaining a healthy BMI, taking regular exercise, and management of their blood pressure, blood sugar and lipid levels through appropriate drug therapy. Statin therapy is recommended for all individuals with a QRISK2 score $\geq 10 \%$.

In individuals undergoing lung cancer screening, the detection or otherwise of coronary artery calcification (CAC) on LDCT may provide additional information pertaining to $\mathrm{CV}$ risk $(7,8)$. CAC reflects underlying atherosclerosis and its presence, in those without a previous history of ischaemic heart disease, is strongly correlated with CV events and all-cause mortality $(3,9,10)$. A simple visual categorisation of $\mathrm{CAC}$ (none, mild, moderate and severe) is equivalent to more detailed assessment e.g. Agatston scoring and can therefore be incorporated into a standard reporting template (11-15). 
Low socioeconomic status (SES) and smoking are associated with increased risk of both lung cancer and CVD $(16,17)$; these factors are also associated with reduced participation in screening trials $(18$ 21). This reflects differing attitudes to health screening according to smoking status $(22,23)$, and smokers are also less likely than non-smokers to seek help with alarm symptoms (24). To address this, we designed a community-based lung screening service, in areas of high deprivation, to increase service accessibility and convenience for these more 'hard-to-reach' groups (25). Screening was targeted at those at most risk, defined according to the $\mathrm{PLCO}_{\mathrm{M} 2012}$ lung cancer risk prediction model at a threshold of $1.51 \%$ or greater, over 6 years. The aim of this study was to determine whether a brief CV risk assessment, using the QRISK2 risk assessment tool, delivered as part of a community-based lung cancer screening programme, was effective in identifying individuals at high risk. We hypothesised that this deprived population would be at high risk of CVD but not be receiving optimal primary prevention, in particular statin therapy. 


\section{Methods}

\subsection{Lung cancer screening service}

A detailed description of the Manchester Lung Screening Pilot has been described elsewhere (25). In brief, all ever smokers, aged 55-74, registered at participating General Practitioner (GP) practices $(n=14)$, were invited to attend a Lung Health Check (LHC), based in convenient community locations near major shopping centres, in deprived areas of Manchester. Never smokers, individuals with a lung cancer diagnosis within 5 years or those on palliative care registers were not eligible to attend. Lung cancer risk was calculated using the $\mathrm{PLCO}_{\mathrm{M} 2012}$ calculator, and those at high risk $\left(\mathrm{PLCO}_{\mathrm{M} 2012} \geq 1.51 \%\right.$ over six years) invited for annual LDCT screening over two screening rounds. Postcodes were recorded to determine Index of Multiple Deprivation 2015 (IMD) rank for England. This is a measure of relative deprivation in small areas (neighbourhoods) of England; areas are ranked from 1 (most deprived) to 32,844 (least deprived) (26).

\subsection{Selection of cases, controls and data collection}

All attendees of the second screening round (June to August 2017) were eligible to participate in this study, which, through the use of structured questionnaires (online supplement), obtained details about smoking status, past medical history [myocardial infarction (MI), angina, cerebrovascular accident (CVA), transient ischaemic attack (TIA), diabetes mellitus (DM), hypertension, hypercholesterolemia, atrial fibrillation (AF), chronic kidney disease and rheumatoid arthritis)], medication use (statin, antihypertensives), family history (first degree relative diagnosed with ischaemic heart disease under 60) and calculation of 10-year cardiovascular disease risk using the QRISK2 online calculator (27). The online calculator includes measurements of systolic blood pressure and cholesterol/HDL ratio, which were not measured in this study, however missing data are assigned by the calculator using age and sexbased average values allowing a risk score to still be calculated. Those with a previous history of MI, angina, stroke or TIA at study entry were excluded from analysis as stipulated by the risk calculator methods (27). In line with current National Institute for Health and Care Excellence (NICE) guidelines, attendees were classed as 'high risk' if their 10-year risk of CVD, as estimated by the QRISK2 calculator, was $\geq 10 \%$ (28). 
Data from screening participants were compared (one-to-one) to age ( \pm 5 years) and sex matched controls, using Health Survey for England (HSE) 2015 data (29). This annual survey on the general health of around 8,000 adults is representative of the general UK population with individual level data freely available online for use in research studies. It includes information on demographics, previous medical, drug and smoking history as well as height and weight, allowing calculation of individual QRISK2 scores. All selected controls answered 'no' to questions regarding 'a condition of the heart and circulatory system' and 'a condition of the nervous system' to exclude those with a potential history of CVD. Postcodes are not provided as part of the HSE dataset and therefore a comparison of IMD deprivation scores between participants and controls is not possible.

\subsection{LDCT Scan}

All LDCT scans (Optima 660, GE Healthcare) used helical acquisition of axial images from lung apices to the costophrenic angles. Imaging was non-triggered and performed without intravenous contrast, in suspended maximal inspiration, with the patient supine and arms above head (scan time 5-10 seconds). Images were reconstructed at $1.25 \mathrm{~mm}$ thickness and at $1.25 \mathrm{~mm}$ increments. CT scans were reported by National Health Service (NHS) Consultant Radiologists with a specific interest in thoracic radiology. CAC was categorised by the reporting radiologist as none, mild, moderate or severe as part of a structured reporting template. This pragmatic categorisation was based on a subjective assessment made by the reporting radiologist without prespecified criteria.

\subsection{Ethics and consenting}

All individuals provided written informed consent to study participation (REC Ref: 17/EE/0092). Clinical data from the screening service was recorded on an ethically approved database (REC Ref: 16/NW/0013).

\subsection{Statistical analysis}

All statistical analysis was conducted using SPSS version 22. Groups were compared using independent T-test (parametric) or Mann-Whitney U Test (non-parametric) for continuous data and $\chi^{2}$ and Fisher's 
exact tests for categorical data. Pearson's correlation coefficient was used for continuous variables.

Statistical significance was defined as a $p$-value $\leq 0.05$. 


\section{Results}

\subsection{Participants}

In total, 958 individuals consented to study participation, representing $80.2 \%(n=958 / 1,194)$ of those attending the second screening round. Thirty-eight were excluded due to incomplete datasets (Figure 1). In those analysed $(n=920)$, mean age was $65.6 \pm 5.4,50.4 \%$ female, $47.5 \%$ current smokers and median IMD deprivation rank 2,848 (IQR 1,110-5,143). There was no significant difference in baseline characteristics between participants and non-participants (data not shown).

\subsection{Cardiovascular disease risk-QRISK2 score}

$206(22.4 \%)$ individuals reported a history of CVD, which included MI ( $\mathrm{n}=93)$, angina $(\mathrm{n}=110)$, stroke $(n=21)$ and/or TIA $(n=61)$. In the $714(77.6 \%)$ participants without established CVD, the median QRISK2 score was 21.1\% (IQR 14.9-29.6) and this was positively correlated with lung cancer risk i.e. PLCO $_{\mathrm{M} 2012}$ score $(\mathrm{r}=0.26, \mathrm{p}<0.001) .93 .1 \%(\mathrm{n}=665 / 714)$ were classified high risk based on a QRISK2 score $\geq 10 \%$ (Figure 2). In the high-risk group, $53.4 \%(n=355 / 665)$ were prescribed a statin and $46.6 \%$ $(n=310 / 665)$ were not. Participants already on statin therapy were found to have a higher median QRISK2 score $(25.7 \%$ vs $18.3 \%, \mathrm{p}<0.001)$ and a higher rate of self-reported hypertension $(64.8 \%$ vs $27.7 \%, \mathrm{p}<0.001)$, DM $(27.9 \%$ vs $6.1 \%, \mathrm{p}<0.001)$ and $\mathrm{AF}(8.7 \%$ vs $3.2 \%, \mathrm{p}=0.03)$ than those not on statin therapy (Table 1). Overall, one third $(33.7 \%$; $=310 / 920)$ of all participants were at high risk of CVD but not receiving primary prevention with statin therapy as recommended by NICE (Figure 1).

\subsection{Comparison with the general population}

Ten-year CVD risk was compared between study participants with no prior history of CVD, and age and sex matched controls from the Health Survey for England $(n=714)$ which is deemed to be representative of the general population. Median 10-year CVD risk was significantly higher than controls (median QRISK2 score 21.1\%, IQR 14.9-29.6 vs. 10.3\%, IQR 6.6-16.2) (p<0.001). Study participants were also more likely to have a high QRISK2 score at both the $\geq 10 \%$ (93.1\% vs $57.1 \%$, $\mathrm{p}<0.001$; OR 10.2 [95\% CI 7.3-14.0]) and $\geq 20 \%$ threshold (54.5\% vs $9.5 \%, \mathrm{p}<0.001$; OR $11.4[95 \%$ CI 8.5-15.2]). The screening population was selected according to smoking history and therefore 
smoking exposure was significantly greater in the screened cohort (Table 2). However, other risk factors were also higher in screening attendees included the prevalence of diabetes $(16.5 \%$ vs. $3.1 \%, p<0.001)$, hypertension ( $45.1 \%$ vs. $1.5 \%, \mathrm{p}<0.001)$ and mean BMI $(28.3 \pm 5.3$ vs. $23.3 \pm 2.6, \mathrm{p}<0.001)$ (Table 2$)$.

\subsection{Coronary artery calcification}

The proportion of participants with any evidence of CAC on LDCT was $74.2 \%(n=683 / 920)$ (Table 3). CAC was more common in those with a previous history of CVD $(81.1 \%, n=167 / 206)$ compared to those without $(72.3 \%, \mathrm{n}=516 / 714 ; \mathrm{p}=0.011)$. In those with a previous history of CVD, there was no statistically significant difference in CAC between individuals with a history of ischaemic heart disease (MI/angina) compared to those with a history of cerebrovascular disease (stroke/TIA) (85.4\% vs 82.6\%; $\mathrm{p}=0.237$ ). Individuals at high risk of CVD were significantly more likely to have any CAC than those at low risk $(74.3 \%$ vs. $44.9 \%$; $<<0.001)$. Participants at high risk already taking a statin had significantly more CAC than those not on a statin $(81.5 \%$ vs. $62.8 \%$; $<<0.001)$; almost 1 in 4 participants who were eligible for primary prevention but were not taking a statin had moderate to severe CAC (23\%) (Table $3)$.

The extent of CAC was also related to history and risk score: in those with established CVD, 55.9\% had either moderate or severe CAC, compared to $32.2 \%$ in those with a high QRISK2 score and $6.1 \%$ in those with a low QRISK2 score. One in four individuals classified as high risk by QRISK2 had no evidence of CAC on LDCT $(25.7 \%, n=171 / 665)$. Conversely, 44.9\% $(n=22 / 49)$ of participants at low risk according to QRISK2 score had evidence of CAC on LDCT including 2 individuals with moderate and 1 individual with severe CAC. 


\section{Discussion}

\section{Summary of main findings}

In this study, we investigated a brief intervention to assess CVD risk as part of a community-based LDCT lung cancer screening programme (25). Twenty-two percent of study participants reported a preexisting diagnosis of CVD. In those with no prior history, 93\% were at high risk, defined as a QRISK2 score $\geq 10 \%$; above this risk threshold statin therapy is recommended by UK national guidelines for the primary prevention of CVD. In our cohort, almost half (47\%) of those at high risk were not taking a statin, this equated to one in three of all screening attendees. Individuals not taking a statin had a significantly lower mean QRISK score, however current smoking rates were higher and almost one in four had moderate or severe CAC suggesting this group may have an unrecognised burden of CV risk, a well-documented issue in more 'hard-to-reach' populations (30).

Compared to age and sex matched controls, screening participants had double the 10-year CVD risk $(21.1 \%$ vs. $10.3 \%, \mathrm{p}<0.001)$ and were ten-times more likely to be classified high risk (OR $10.2 ; 95 \%$ CI 7.3-14.0). This is partly due to screening selection criteria, which in this cohort was based on 6-year lung cancer risk, calculated using the $\mathrm{PLCO}_{\mathrm{M} 2012}$ model (at a threshold of $\geq 1.51 \%$ ). PLCO $_{\mathrm{M} 2012}$ score was significantly correlated with QRISK $(\mathrm{r}=0.26, \mathrm{p}<0.001)$, highlighting the common risk factors shared by the two diseases. Although smoking exposure was a major driver of CV risk other factors were also significantly raised in the screened cohort including BMI and the prevalence of diabetes and hypertension. Another possible explanation for this difference may have been the location of screening in highly deprived areas of Manchester, the median deprivation rank of screening attendees was in the lowest decile for England.

\section{Strengths and limitations of approach}

The integration of a non-radiological CVD risk prediction tool within a lung cancer screening programme is a novel approach. The pragmatic incorporation of QRISK alongside other aspects of the Lung Health Check was straightforward and identified a large number of people at high risk. However, this was not a robust assessment of $\mathrm{CV}$ health, which would require measurement of factors such as 
blood pressure, blood glucose level and cholesterol. To address this, results were forwarded to GPs with a recommendation for further assessment. The lack of blood pressure and cholesterol measurements in this study does impact the precision of risk factor estimation, however we do not believe their inclusion would have demonstrably altered our main findings.

In future work, we will investigate whether immediate reporting of QRISK score might be a valuable 'teachable moment' to ensure people are aware of their own risk and provide advice about how to address this. One potential weakness to this approach is recall bias; the location of the service in supermarket car parks did not allow medical records to be checked to verify responses. Risk calculations which rely on participants self-reporting aspects of their medical and drug history may therefore be inaccurate.

Health Survey for England controls are highly representative of the general population and thus a reliable way of avoiding healthy control bias as individuals are selected at random based on postcodes, escaping the potential issue of self-recruitment. Although in this study the QRISK2 score was used, as recommended by the UK based NICE guidelines, it should be noted the majority of variables used in this risk score are comparable to those used in other CVD risk calculators, including the Framingham risk calculator (31), and therefore other risk score calculators more relevant to local populations could readily be used in screening services.

\section{Future work}

The inclusion of CAC reporting with LDCT lung cancer screening has been described in a number of studies $(7,8,13)$ yet no agreed protocol has been established on how best to use this information. Evidence of CAC on LDCT is associated with increased risk of cardiovascular events and mortality (3, 9, 10). Comparing radiological and non-radiological cardiovascular risk assessment in the context of lung cancer screening has not been studied. In this study, we demonstrated a strong association between QRISK2 score and the presence of CAC. A QRISK2 score of $\geq 10 \%$ was associated with higher levels of CAC on LDCT $(p<0.001)$. However, $46 \%$ of participants with a low risk QRISK2 score $(<10 \%)$ had 
some CAC on LDCT. It is also worth noting the use of statin therapy is associated with increased CAC on $\mathrm{CT}$, which is thought represent plaque repair and stabilization, without a corresponding increase in coronary atheroma volume or risk of future cardiac events (32). This could contribute to the difference in CAC levels detected in those taking and not taking a statin. Given that CAC on LDCT is a robust prognostic measure of potentially fatal cardiovascular events (13), it could be argued a more thorough cardiology assessment for this 'low risk' group could be of benefit. Identification of previously unrecognised risk factors might increase the QRISK score in some of these individuals. In contrast, a quarter of participants with a high risk QRISK2 score $(\geq 10 \%)$ and one in five individuals with established CVD had no evidence of CAC. Incorporation of CAC score alongside standard clinical risk factors has been developed in the Multi-Ethnic Study of Atherosclerosis (MESA) (33). This calculation could not be undertaken in our study because total / HDL cholesterol and blood pressure were not measured. This demonstrates the importance of identifying and agreeing on how best to assess CVD risk in lung cancer screening services and could be the subject of future studies.

\section{Conclusion}

Our results demonstrate that selection of a lung cancer screening population based on the PLCO $_{\mathrm{M} 2012}$ model selects individuals who are at high risk of CVD based on clinical risk score using QRISK and the prevalence of CAC reported on LDCT. The incorporation of a simple CVD risk assessment tool into a lung cancer screening programme is feasible and in this cohort, identified a significant number of individuals at high risk of CVD who might benefit from thorough cardiovascular assessment and primary prevention including statin therapy. Our community-based Lung Health Check approach was successful in engaging individuals from deprived areas (25). This may provide an opportunity to engage individuals who have not previously attended health promotion initiatives, such as the NHS Health Check (34), and thereby address a leading cause of morbidity and mortality in this group. This approach would not only have beneficial health implications for these high-risk populations but could also improve cost-effectiveness of such a screening programme (35). 


\section{References}

1. National Lung Screening Trial Research T, Aberle DR, Adams AM, Berg CD, Black WC, Clapp JD, et al. Reduced lung-cancer mortality with low-dose computed tomographic screening. N Engl J Med. 2011;365(5):395-409.

2. Chiles C, Paul NS. Beyond lung cancer: a strategic approach to interpreting screening computed tomography scans on the basis of mortality data from the National Lung Screening Trial. J Thorac Imaging. 2013;28(6):347-54.

3. Shemesh J. Coronary artery calcification in clinical practice: what we have learned and why should it routinely be reported on chest CT? Ann Transl Med. 2016;4(8):159.

4. Hippisley-Cox J, Coupland C, Vinogradova Y, Robson J, Minhas R, Sheikh A, et al. Predicting cardiovascular risk in England and Wales: prospective derivation and validation of QRISK2. BMJ. 2008;336(7659):1475-82.

5. NICE. Cardiovascular disease: risk assessment and reduction, including lipid modification 2014(CG181).

6. Hippisley-Cox J, Coupland C, Brindle P. Development and validation of QRISK3 risk prediction algorithms to estimate future risk of cardiovascular disease: prospective cohort study. BMJ. 2017;357:j2099.

7. Collins FS, Varmus H. A new initiative on precision medicine. N Engl J Med. 2015;372(9):793-5.

8. Polonsky TS, McClelland RL, Jorgensen NW, Bild DE, Burke GL, Guerci AD, et al. Coronary artery calcium score and risk classification for coronary heart disease prediction. JAMA. 2010;303(16):1610-6. 9. Pletcher MJ, Tice JA, Pignone M, Browner WS. Using the coronary artery calcium score to predict coronary heart disease events: a systematic review and meta-analysis. Arch Intern Med. 2004;164(12):128592.

10. Rennenberg RJ, Kessels AG, Schurgers LJ, van Engelshoven JM, de Leeuw PW, Kroon AA. Vascular calcifications as a marker of increased cardiovascular risk: a meta-analysis. Vasc Health Risk Manag. 2009;5(1):185-97.

11. Xie X, Zhao Y, de Bock GH, de Jong PA, Mali WP, Oudkerk M, et al. Validation and prognosis of coronary artery calcium scoring in nontriggered thoracic computed tomography: systematic review and metaanalysis. Circ Cardiovasc Imaging. 2013;6(4):514-21.

12. Schulman-Marcus J, Valenti V, Hartaigh BO, Gransar H, Truong Q, Giambrone A, et al. Prognostic utility of coronary artery calcium scoring in active smokers: a 15-year follow-up study. Int J Cardiol. 2014;177(2):581-3.

13. Rasmussen T, Kober L, Abdulla J, Pedersen JH, Wille MM, Dirksen A, et al. Coronary artery calcification detected in lung cancer screening predicts cardiovascular death. Scand Cardiovasc J. 2015;49(3):159-67.

14. Htwe $\mathrm{Y}, \mathrm{Cham} \mathrm{MD}$, Henschke $\mathrm{Cl}$, Hecht $\mathrm{H}$, Shemesh J, Liang M, et al. Coronary artery calcification on low-dose computed tomography: comparison of Agatston and Ordinal Scores. Clin Imaging. 2015;39(5):799802.

15. Chiles C, Duan F, Gladish GW, Ravenel JG, Baginski SG, Snyder BS, et al. Association of Coronary Artery Calcification and Mortality in the National Lung Screening Trial: A Comparison of Three Scoring Methods. Radiology. 2015;276(1):82-90.

16. Alter DA, Franklin B, Ko DT, Austin PC, Lee DS, Oh PI, et al. Socioeconomic status, functional recovery, and long-term mortality among patients surviving acute myocardial infarction. PLoS One. 2014;8(6):e65130.

17. Albert MA, Glynn RJ, Buring J, Ridker PM. Impact of traditional and novel risk factors on the relationship between socioeconomic status and incident cardiovascular events. Circulation. 2006;114(24):2619-26.

18. Lang SJ, Abel GA, Mant J, Mullis R. Impact of socioeconomic deprivation on screening for cardiovascular disease risk in a primary prevention population: a cross-sectional study. BMJ Open. 2016;6(3):e009984.

19. Hestbech MS, Siersma V, Dirksen A, Pedersen JH, Brodersen J. Participation bias in a randomised trial of screening for lung cancer. Lung Cancer. 2011;73(3):325-31.

20. McRonald FE, Yadegarfar G, Baldwin DR, Devaraj A, Brain KE, Eisen T, et al. The UK Lung Screen (UKLS): demographic profile of first 88,897 approaches provides recommendations for population screening. Cancer Prev Res (Phila). 2014;7(3):362-71.

21. National Lung Screening Trial Research T, Aberle DR, Adams AM, Berg CD, Clapp JD, Clingan KL, et al. Baseline characteristics of participants in the randomized national lung screening trial. J Natl Cancer Inst. 2010;102(23):1771-9. 
22. Silvestri GA, Nietert PJ, Zoller J, Carter C, Bradford D. Attitudes towards screening for lung cancer among smokers and their non-smoking counterparts. Thorax. 2007;62(2):126-30.

23. Patel D, Akporobaro A, Chinyanganya N, Hackshaw A, Seale C, Spiro SG, et al. Attitudes to participation in a lung cancer screening trial: a qualitative study. Thorax. 2012;67(5):418-25.

24. Friedemann Smith C, Whitaker KL, Winstanley K, Wardle J. Smokers are less likely than non-smokers to seek help for a lung cancer 'alarm' symptom. Thorax. 2016;71(7):659-61.

25. Crosbie PA, Balata H, Evison M, Atack M, Bayliss-Brideaux V, Colligan D, et al. Implementing lung cancer screening: baseline results from a community-based 'Lung Health Check' pilot in deprived areas of Manchester. Thorax. 2018.

26. Department for Communities and Local Government. English indices of deprivation 2015 [cited 2016 4th November]. Available from: http://imd-by-postcode.opendatacommunities.org/.

27. QRISK2. The QRISK2 Cardiovascular Disease Risk Calculator 20172017 [updated 10/02/2018.

Available from: https://qrisk.org/2017/.

28. Lipid Modification: Cardiovascular Risk Assessment and the Modification of Blood Lipids for the Primary and Secondary Prevention of Cardiovascular Disease. National Institute for Health and Clinical Excellence: Guidance. London2014.

29. NHS Digital. Health Survey for England. 2015.

30. Kitson SJ, Lindsay J, Sivalingam VN, Lunt M, Ryan NAJ, Edmondson RJ, et al. The unrecognized burden of cardiovascular risk factors in women newly diagnosed with endometrial cancer: A prospective case control study. Gynecol Oncol. 2018;148(1):154-60.

31. Anderson KM, Odell PM, Wilson PW, Kannel WB. Cardiovascular disease risk profiles. Am Heart J. 1991;121(1 Pt 2):293-8.

32. Puri R, Nicholls SJ, Shao M, Kataoka Y, Uno K, Kapadia SR, et al. Impact of statins on serial coronary calcification during atheroma progression and regression. J Am Coll Cardiol. 2015;65(13):1273-82.

33. McClelland RL, Jorgensen NW, Budoff M, Blaha MJ, Post WS, Kronmal RA, et al. 10-Year Coronary Heart Disease Risk Prediction Using Coronary Artery Calcium and Traditional Risk Factors: Derivation in the MESA (Multi-Ethnic Study of Atherosclerosis) With Validation in the HNR (Heinz Nixdorf Recall) Study and the DHS (Dallas Heart Study). J Am Coll Cardiol. 2015;66(15):1643-53.

34. Robson J, Dostal I, Sheikh A, Eldridge S, Madurasinghe V, Griffiths C, et al. The NHS Health Check in England: an evaluation of the first 4 years. BMJ Open. 2016;6(1):e008840.

35. Cressman S, Peacock SJ, Tammemagi MC, Evans WK, Leighl NB, Goffin JR, et al. The Cost-Effectiveness of High-Risk Lung Cancer Screening and Drivers of Program Efficiency. J Thorac Oncol. 2017. 
Table 1. Characteristics of those at high risk of CVD stratified according to statin therapy.

\begin{tabular}{|c|c|c|c|c|c|}
\hline \multirow{2}{*}{\multicolumn{2}{|c|}{ Variable }} & \multirow[b]{2}{*}{ All Participants } & \multicolumn{2}{|c|}{ QRISK Score $\geq 10 \%$ ( $\mathrm{n}=665)$} & \multirow[b]{2}{*}{$\mathrm{p}$ value } \\
\hline & & & On a statin & $\begin{array}{c}\text { Not on a } \\
\text { statin }\end{array}$ & \\
\hline \multicolumn{2}{|c|}{ Number of participants (\%) } & $920(100.0)$ & $355(38.6)$ & $310(33.7)$ & - \\
\hline \multicolumn{2}{|c|}{ Mean age (years $\pm \mathrm{SD}$ ) } & $65.6(5.4)$ & $66.5(5.3)$ & $64.9(5.2)$ & 0.645 \\
\hline \multicolumn{2}{|c|}{$\operatorname{Sex} \mathrm{M} / \mathrm{F}(\mathrm{F} \%)$} & $456 / 464(50.4)$ & $182 / 173(48.7)$ & $142 / 168(54.2)$ & 0.160 \\
\hline \multicolumn{2}{|c|}{ Mean BMI $( \pm$ SD) } & $28.6(5.3)$ & $29.2(5.3)$ & $27.5(5.1)$ & 0.605 \\
\hline \multicolumn{2}{|c|}{ Median QRISK Score (\%) (IQR) } & NA & $\begin{array}{c}25.7 \\
(19.4-34.9)\end{array}$ & $\begin{array}{c}18.3 \\
(14.2-24.8)\end{array}$ & $<0.001$ \\
\hline \multirow{2}{*}{$\begin{array}{c}\text { Smoking status } \\
(\%)\end{array}$} & Current & $437(47.5)$ & $161(45.4)$ & $164(52.9)$ & \multirow{2}{*}{0.052} \\
\hline & Former & $483(52.5)$ & $194(54.6)$ & $146(47.1)$ & \\
\hline \multicolumn{2}{|c|}{ Angina/MI in $1^{\text {st }}$ degree relative age $<60(\%)$} & $288(31.3)$ & $108(30.4)$ & $84(27.1)$ & 0.345 \\
\hline \multicolumn{2}{|c|}{ Hypertension (\%) } & $455(49.5)$ & $230(64.8)$ & $86(27.7)$ & $<0.001$ \\
\hline \multicolumn{2}{|c|}{ Atrial Fibrillation (\%) } & $64(7.0)$ & $31(8.7)$ & $10(3.2)$ & 0.003 \\
\hline \multicolumn{2}{|c|}{ Chronic Kidney Disease (\%) } & $23(2.5)$ & $10(2.8)$ & $3(1.0)$ & 0.086 \\
\hline \multicolumn{2}{|c|}{ Rheumatoid Arthritis (\%) } & $122(13.3)$ & $49(13.8)$ & $32(10.3)$ & 0.171 \\
\hline \multicolumn{2}{|c|}{ Diabetes Mellitus (\%) } & $183(19.9)$ & $99(27.9)$ & $19(6.1)$ & $<0.001$ \\
\hline
\end{tabular}


Table 2. Characteristics of study participants with Health Survey for England (2015) controls.

\begin{tabular}{|c|c|c|c|c|}
\hline \multicolumn{2}{|c|}{ Variable } & $\begin{array}{c}\text { Study } \\
\text { Participants }\end{array}$ & HSE Controls & $\mathrm{p}$ value \\
\hline \multicolumn{2}{|c|}{ Participants with valid QRISK2 score } & 714 & 714 & - \\
\hline \multicolumn{2}{|c|}{ Mean age (years \pm SD) } & $65.3(5.4)$ & $62.3(5.7)$ & 0.86 \\
\hline \multicolumn{2}{|c|}{ Sex M/F (F\%) } & $390 / 324(45.4)$ & $390 / 324(45.4)$ & 1.0 \\
\hline \multicolumn{2}{|c|}{ Mean BMI $( \pm$ SD $)$} & $28.3(5.3)$ & $23.3(2.6)$ & $<0.001$ \\
\hline \multirow{3}{*}{$\begin{array}{c}\text { Smoking status } \\
(\%)\end{array}$} & Current & $349(48.9)$ & $119(16.7)$ & \multirow{3}{*}{$<0.001$} \\
\hline & Former & $365(51.1)$ & $218(30.5)$ & \\
\hline & Never & $0(0)$ & $377(52.8)$ & \\
\hline \multicolumn{2}{|c|}{ Diabetes Mellitus (\%) } & $118(16.5)$ & $22(3.1)$ & $<0.001$ \\
\hline \multicolumn{2}{|c|}{ Hypertension } & $322(45.1)$ & $11(1.5)$ & $<0.001$ \\
\hline \multicolumn{2}{|c|}{ Median QRISK score (IQR) } & $21.1(14.9-29.6)$ & $10.3(6.6-16.2)$ & $<0.001$ \\
\hline \multicolumn{2}{|c|}{ Median IMD rank (IQR) } & $2848(1110-5143)$ & - & - \\
\hline
\end{tabular}


Table 3. Extent of CAC on LDCT stratified according to CVD history,

QRISK2 score and statin therapy.

\begin{tabular}{|c|c|c|c|c|c|c|c|}
\hline \multirow[b]{2}{*}{$\begin{array}{c}\text { Extent of } \\
\text { CAC }\end{array}$} & \multirow[b]{2}{*}{$\begin{array}{c}\text { Established } \\
\text { CVD }\end{array}$} & \multicolumn{3}{|c|}{ No history of CVD } & \multicolumn{3}{|c|}{ Eligible for primary prevention } \\
\hline & & $\begin{array}{c}\text { QRISK2 } \\
<10 \% \\
(\%)\end{array}$ & $\begin{array}{c}\text { QRISK2 } \\
\geq 10 \% \\
(\%)\end{array}$ & $\mathrm{p}$ value & $\begin{array}{c}\text { Taking a } \\
\text { statin } \\
(\%)\end{array}$ & $\begin{array}{c}\text { Not taking a } \\
\text { statin } \\
(\%)\end{array}$ & $\mathrm{p}$ value \\
\hline None & $39(18.9)$ & $27(55.1)$ & $171(25.7)$ & \multirow{4}{*}{$<0.001$} & $67(18.5)$ & $131(37.2)$ & \multirow{4}{*}{$<0.001$} \\
\hline Mild & $52(25.2)$ & $19(38.8)$ & $280(42.1)$ & & $159(43.9)$ & $140(39.8)$ & \\
\hline Moderate & $58(28.2)$ & $2(4.1)$ & $150(22.6)$ & & $89(24.6)$ & $63(17.9)$ & \\
\hline Severe & $57(27.7)$ & $1(2.0)$ & $64(9.6)$ & & $47(13.0)$ & $18(5.1)$ & \\
\hline Total & 206 & 49 & 665 & - & 362 & 352 & \\
\hline
\end{tabular}




\section{Figure legends}

Figure 1. Flow of participants through study;

(* = eligible for statin therapy according to NICE guidance)

Figure 2. Boxplot demonstrating distribution of $\mathrm{CV}$ risk (range - minimum to maximum), based on QRISK2 scores, in screening participants $(\mathrm{n}=714)$ and HSE controls $(\mathrm{n}=714)$. 


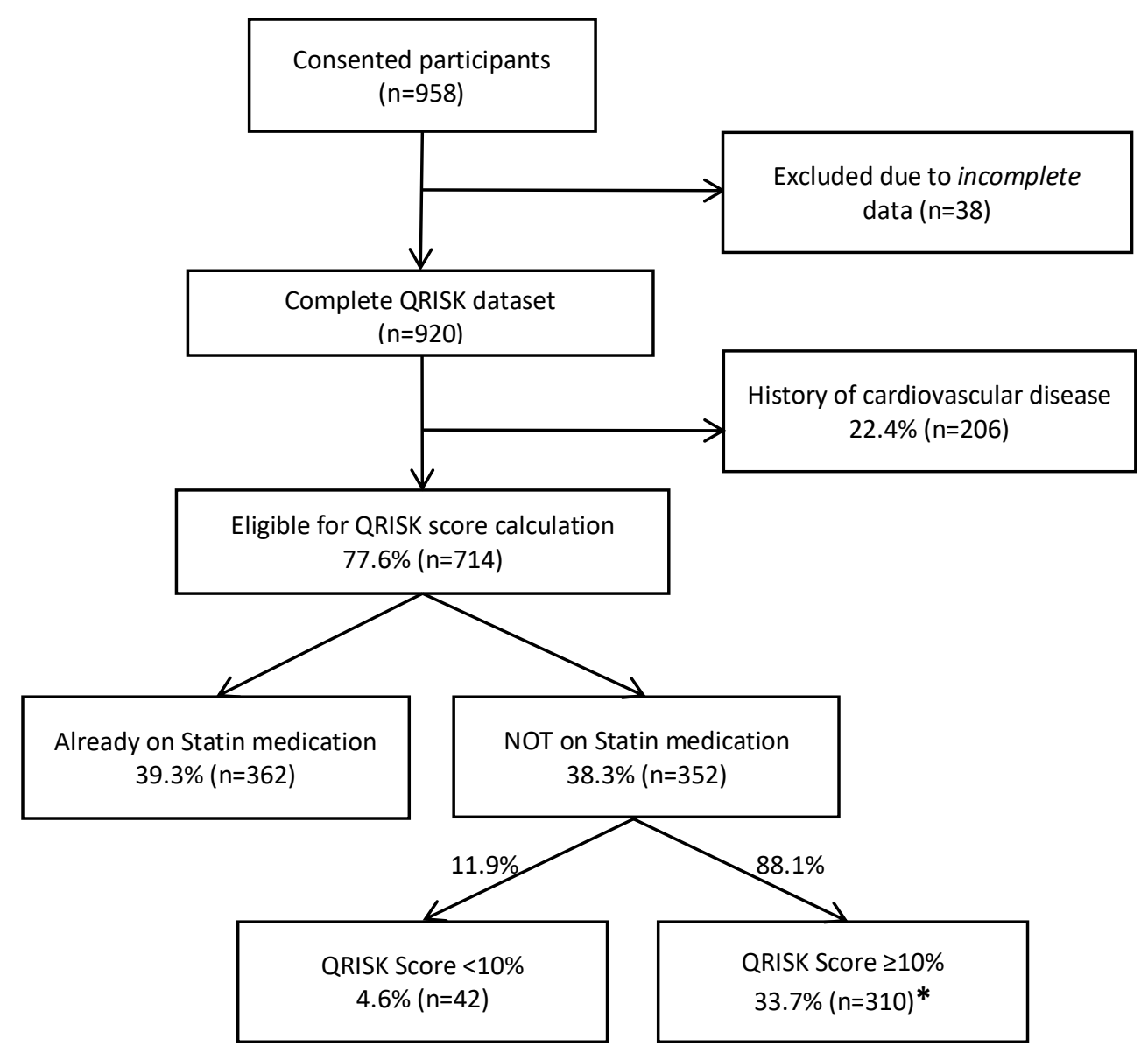




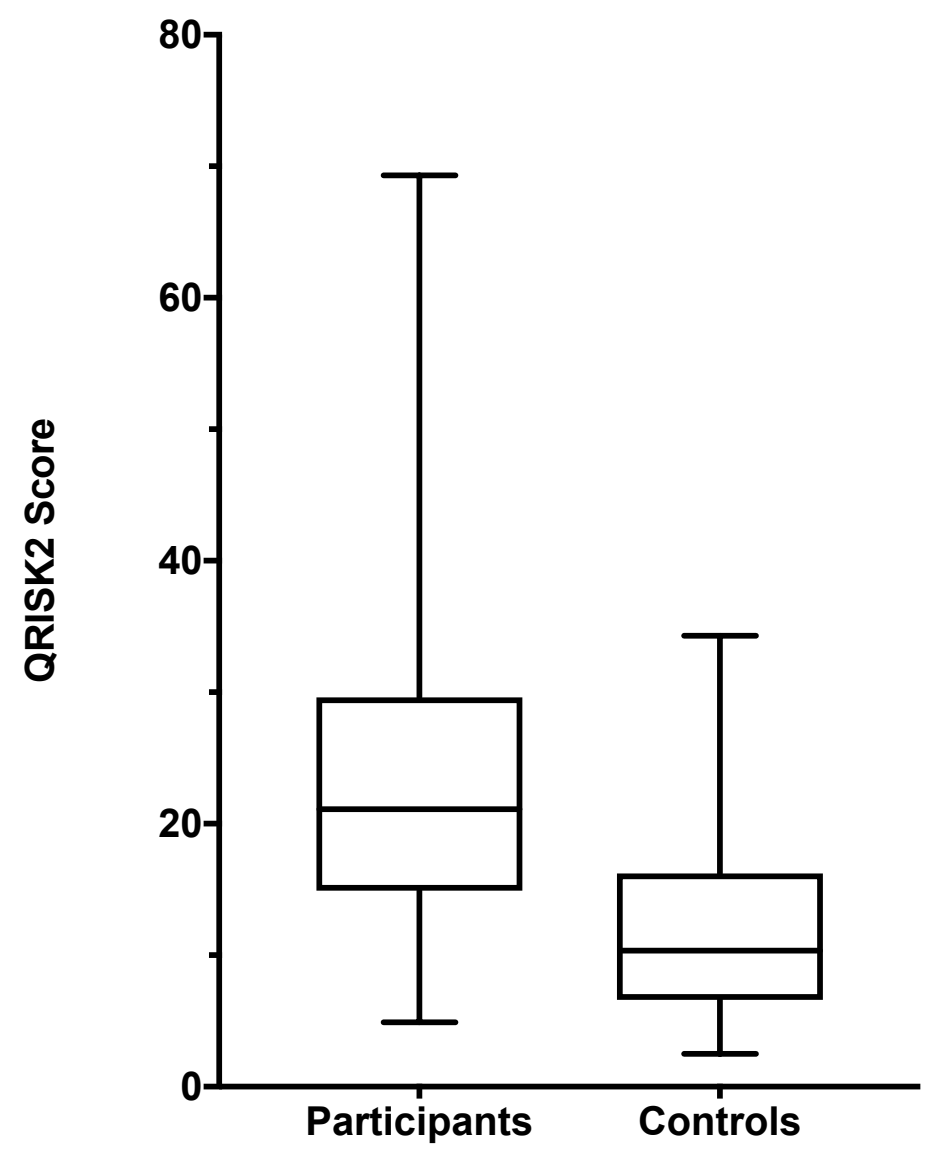




\section{Highlights}

- $93 \%$ participants at high risk of cardiovascular disease (CVD) (QRISK2 score $\geq 10 \%$ ).

- 1 in 3 of all screening attendees at high risk of CVD but not taking a statin.

- Those screened had double the CVD risk than controls ( $21.1 \%$ vs. $10.3 \%, \mathrm{p}<0.001)$.

- And 10-times more likely to be high risk than controls (OR 10.2; 95\% CI 7.3-14.0).

- Lung cancer $\left(\mathrm{PLCO}_{\mathrm{M} 2012}\right)$ and CVD risk (QRISK) scores correlated $(\mathrm{r}=0.26, \mathrm{p}<0.001)$. 